\title{
SUPERVISORS' ASSESSMENT ACCORDING TO BOST METHOD IN A CHOSEN POLISH COMPANY
}

The main subject of the research presented in this paper is assessment of Polish supervisors with use of 4E+1P principle, 12 golden rules and Toyota's principles. This is a part of research conducted within the confines of BOST method, based on the rules of Toyota's system. This test method can be successfully used both in production and service institutions. There are two versions of the survey questionnaire: for supervisors and staff. The questionnaire includes also: the most important areas of improvement, visual control of factors, elements of the manufacturing process, competitive products, assessment of the supervisors and manufacturing processes. The results of research are presented as tables and bar charts.

Keywords: BOST method, 4E+1P principle, 12 golden rules, Toyota's principles, supervisor

\section{Introduction}

The BOST method presented in papers $[1,2]$ was used for carrying out the research. This test method, based on the Toyota's production system can be successfully used both in production and service institutions.

There are two versions of the survey questionnaire in this study: for supervisors and staff. The questionnaire includes: the most important areas of improvement, visual control of factors, elements of the manufacturing process, assessment of the supervisors, competitive products and manufacturing processes. The final part of the survey includes the respondent's birth certificate and determines the nature of the business. With use of the BOST method a human resources company can be characterized. This method includes also a SERVQUAL method questionnaire [3] which measures quality of service.

\section{Description of research problem} ing to:

Development of the problem was based on three issues relat-

1. Assessment according to $4 \mathrm{E}+1 \mathrm{P}$ principles, based on 5 features: $1 \mathrm{E}$ - Is full of enthusiasm all day long, $2 \mathrm{E}$ - Is able to encourage others to take actions, 3E - Makes decisions fast, 4E Knows how to implement decisions, 1P - Cares for the success by co-workers.

2. Assessment according to golden rules based on 12 features: KA - Sets good example, KB - Communicates about goals of actions, $\mathrm{KC}$ - Informs about news in the company, KD - Asks staffs about advice, KE - Gives support during performance of tasks, KF - Directs and requires, KG - Allows to improve work independently, KH - Prizes for good work, KI - Thanks openly, KK - Criticizes in discreet manner, KL - Forgives and encourages to achievement of good results, $\mathrm{KN}$ - Is open to ideas by the staff.

3. Toyota's principles that is what leaders do?, based on 8 features: KP - Improves work in his team, KR - Cares if the team lives by company's vision, KS - Influences with energy and positive attitude, KT - Is open, KV - Is confident while decision-making, KW - Cares if his questions are followed by actions, KU - His behavior inspires for learning, KZ - Is success-driven.

The 4E+1P principles [4] are used for assessment of the candidates during interviews for managerial positions. The twelve golden rules [5] contain comprehensive characteristics of a person and can be successfully used during investigations. Toyota has developed leader traits (8ZT) which can also allow for revealing a number of supervisor traits [6].

The workers have to agree or disagree with all statements divided in these 3 groups. In this way it was possible to indicate main features of the supervisor according to the interviewed workers.

\section{Characteristics of research company}

Company X started its activities in 1982. Manufacturing plant with technical facilities is located in Sosnowiec.

From the beginning, the company is associated with the automotive industry. In this regard, the company performs technical services for the design, execution and assembly. It designs and manufactures technical equipment of production lines, mainly: pen-

\footnotetext{
* Manuela Konstanciak, Stanisław Borkowski, Marta Jagusiak-Kocik

Institute of Engineering Production, Faculty of Management, Czestochowa University of Technology, Czestochowa, Poland,

E-mail: manuela@gazeta.pl
} 
dants to transport the body of a car, car parts (doors, fuel tanks, seats, etc.), storage pallets, as well as trucks to transport the sequence of components from storage to the cost assembly/production. In addition, it manufactures auxiliary equipment used in mass and small series production for the automotive and other industries.

The company's portfolio also includes equipment and tools for hot extrusion of aluminum profiles. These include the device for the separation of the forming dies, conveyor production lines, both predefined and generated waste products (roller, apron, chain conveyors). In cooperation with foreign companies, the company $\mathrm{X}$ produces covers and roofs for recreational and commercial sports halls, which creates a support structure. The company X designs and produces construction with very complex shapes and narrow tolerances.

\section{Structure of the interviewed employees}

Among the employees of the company X the survey BOST, on the basis of which immaterial stores occurring in the enterprise were evaluated, was conducted. The study involved 25 workers selected at random: 5 white-collar workers (doing office work) and 20 bluecollar workers (doing production work).

The human resources of the company, which are presented in Table 1, are one of the criteria of the research. These resources were divided by gender, education, age, work experience, place of work.

Percentage fraction of the structure of workers

Tab. 1

in a research company according to: a) gender,

b) education, c) age, d) work experience, e) place of work.

a)

\begin{tabular}{|c|c|}
\hline Gender & Value [\%] \\
\hline Man & 96 \\
\hline Woman & 4 \\
\hline
\end{tabular}

b)

\begin{tabular}{|c|c|}
\hline Education & Value [\%] \\
\hline Elementary & 4 \\
\hline Vocational & 8 \\
\hline Secondary & 68 \\
\hline Higher & 20 \\
\hline
\end{tabular}

c)

\begin{tabular}{|c|c|}
\hline Age & Value [\%] \\
\hline below 30 years & 16 \\
\hline $\mathbf{3 1}$ - $\mathbf{4 0}$ years & 60 \\
\hline $\mathbf{4 1}-\mathbf{5 0}$ years & 12 \\
\hline $\mathbf{5 1}-\mathbf{5 5}$ years & 4 \\
\hline $\mathbf{5 6}-\mathbf{6 0}$ years & 4 \\
\hline $\mathbf{6 1}-\mathbf{6 5}$ years & 4 \\
\hline
\end{tabular}

d)

\begin{tabular}{|c|c|}
\hline Work experience & Value [\%] \\
\hline below 5 years & 16 \\
\hline 6 - 10 years & 28 \\
\hline $\mathbf{1 1}-\mathbf{1 5}$ years & 20 \\
\hline $\mathbf{1 6}-\mathbf{2 0}$ years & 12 \\
\hline $\mathbf{2 1}-\mathbf{2 5}$ years & 8 \\
\hline $\mathbf{2 6}-\mathbf{3 0}$ years & 4 \\
\hline $\mathbf{3 1}-\mathbf{3 5}$ years & 8 \\
\hline $\mathbf{3 6}-\mathbf{4 0}$ years & 4 \\
\hline
\end{tabular}

e)

\begin{tabular}{|c|c|}
\hline Place of work & Value [\%] \\
\hline Second & 48 \\
\hline Third & 32 \\
\hline Fourth & 20 \\
\hline
\end{tabular}

From the conducted survey in terms of human resources it results that in the company $\mathrm{X}$ men constitute a larger number of employees than women. Men constitute $96 \%$ of the employees, while women are only $4 \%$. It is obvious that the automotive industry is a typical industry for men.

The company is dominated by workers with secondary education who constitute $68 \%$. The second group consists of people with higher education who include $20 \%$. It is possible to notice that the company hires mainly educated people ( $88 \%$ employees with at least secondary education).

Most numerous age group constitutes $60 \%$ of employees in the company, these are persons aged $31-40$ years, $16 \%$ were younger than 30 years. It means that the company hires mainly young people (76\% below 40 years).

Analyzing the work experience it can be seen that most people has been working in the company for 6 - 10 years (28\%). It is moderate work experience allowing for accustoming to activities and becoming intimate with the entire crew. $20 \%$ of people are about slightly bigger internship from 11 - 15 years which also supports better atmosphere at the work. People, who started their work in the company less than 5 years ago, represent $16 \%$ of all employees. Concluding, $64 \%$ of the workers started their work in the company less than 15 years ago. It means that they are already experienced but because of their young age they are more open for new technology.

For $48 \%$ of employees the research company is the second place of work. It should be emphasized that for none of the employees the company $\mathrm{X}$ is their first place of work. It means that all employees worked before somewhere else and they already have some work experience. The number of jobs (place of work) is another element of the investigation in the survey. For $48 \%$ of employees this workplace is their second job. It is important that none of the workers indicated their first place of work. It means that the research 
company is not the first place of work for employees; they already gained experience somewhere else.

\section{Supervisors' assessment according to different tests}

Results of characteristics of supervisors based on the $4 \mathrm{E}+1 \mathrm{P}$ principles are presented in Table 2 . Their graphic interpretation is presented in Fig. 1.

Assessment's structure according to the 4E+1P principles

Tab. 2

\begin{tabular}{|c|c|c|c|c|c|}
\hline \multirow{2}{*}{ Result } & \multicolumn{5}{|c|}{ Denotation of principle [\%] } \\
\cline { 2 - 6 } & $\mathbf{1 E}$ & $\mathbf{2 E}$ & $\mathbf{3 E}$ & $\mathbf{4 E}$ & $\mathbf{1 P}$ \\
\hline YES & 40 & 64 & 64 & 92 & 48 \\
\hline NO & 60 & 36 & 36 & 8 & 52 \\
\hline
\end{tabular}

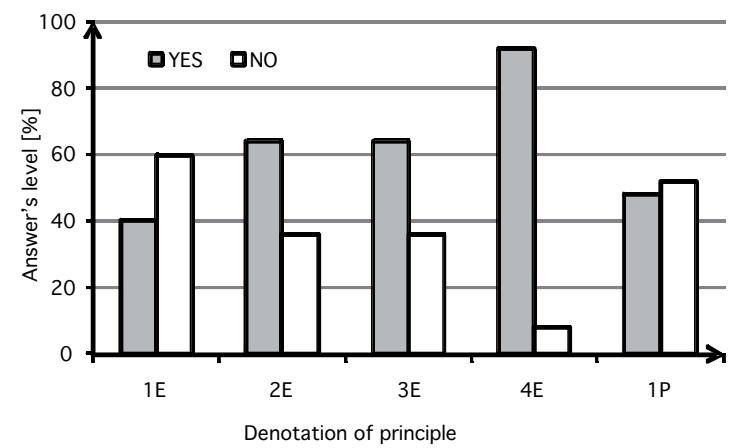

Fig. 1 Supervisor's assessment characteristics based on the $4 E+1 P$ principles - rating structure

According to the $4 \mathrm{E}+\mathrm{P}$ principles an ability of $4 \mathrm{~F}$ - To know how to implement decision is the most important feature of the supervisor amount respondents ( $96 \%$ of YES). Features: 2E - To be able to encourage others to take actions, 3E - To make decisions fast are also highly assessed (64\% of YES). Unfortunately according to the respondents the supervisor $1 \mathrm{E}$ - in not full of enthusiasm all day long $(60 \%$ of NO). During the assessment of superiors according to the $4 \mathrm{E}+\mathrm{P}$ principles a vast number of employees of the company $\mathrm{X}$ concluded that the most important feature, representing $92 \%$ of the possession of the superior, is $4 \mathrm{E}-$ To know how to implement decisions. $2 \mathrm{E}$ - To be able to encourage others to take actions and $3 \mathrm{E}-\mathrm{To}$ make decisions fast are also important - 64\% of respondents think in this way. $60 \%$ of respondents responded "NO", taking into account whether the supervisor 1E - Is full of enthusiasm all day long.
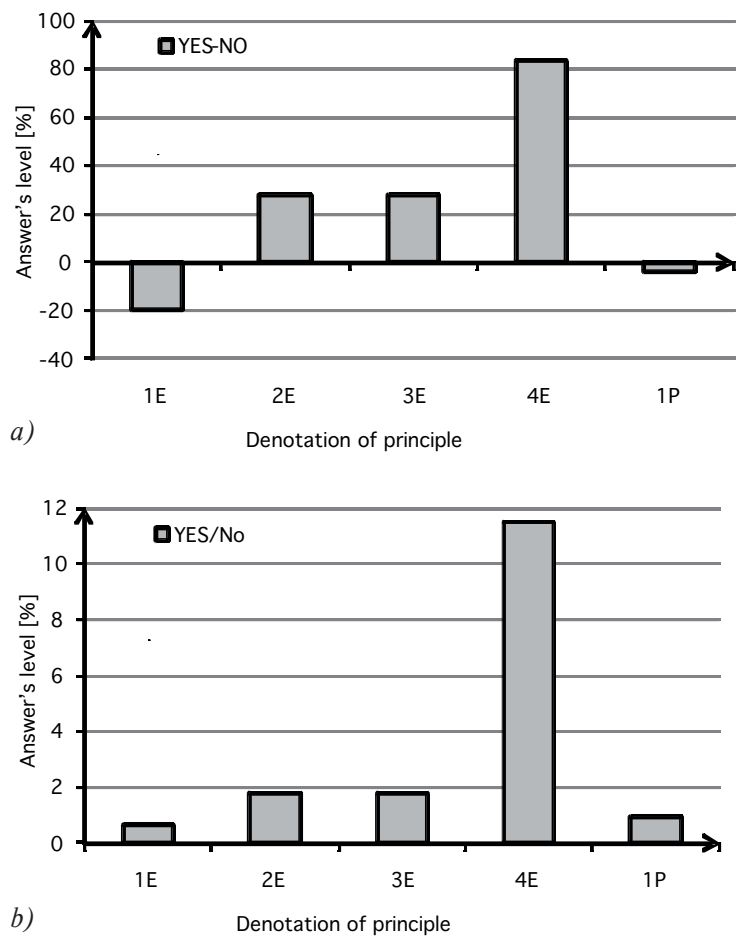

Fig. 2 Supervisor's assessment characteristics based on the $4 E+1 P$ principles:

a) difference YES-NO, b) quotient YES/NO.

To visualize the difference between YES and NO answers, the difference and quotient of these answers were calculated. The results in case of the 4E+1P principles are shown in Fig. 2.

In 3 cases: $2 \mathrm{E}$ - Is able to encourage others to take actions, $3 \mathrm{E}-$ Makes decisions fast, $4 \mathrm{E}$ - Knows how to implement decisions, the difference YES-NO is above 0, what means that in these cases the employees often answered yes, especially in case of 4E. If it comes to the quotient of YES/NO, it is possible to be seen that in the case of element $4 \mathrm{E}$ - Knows how to implement decisions, respondents answered YES almost 12 times more often than NO.

\begin{tabular}{|c|c|c|c|c|c|c|c|c|c|c|c|c|}
\hline \multirow{2}{*}{ Result } & \multicolumn{12}{|c|}{ Denotation of principle [\%] } \\
\hline & KA & KB & KC & KD & KE & $\mathbf{K F}$ & KG & KH & KI & KK & KL & KN \\
\hline YES & 80 & 88 & 64 & 36 & 88 & 96 & 68 & 44 & 36 & 72 & 72 & 80 \\
\hline NO & 20 & 12 & 36 & 64 & 12 & 4 & 32 & 56 & 64 & 28 & 28 & 20 \\
\hline
\end{tabular}


Results of characteristics of supervisors based on the 12 golden rules are presented in Table 3. Their graphic interpretation is presented in Fig. 3.

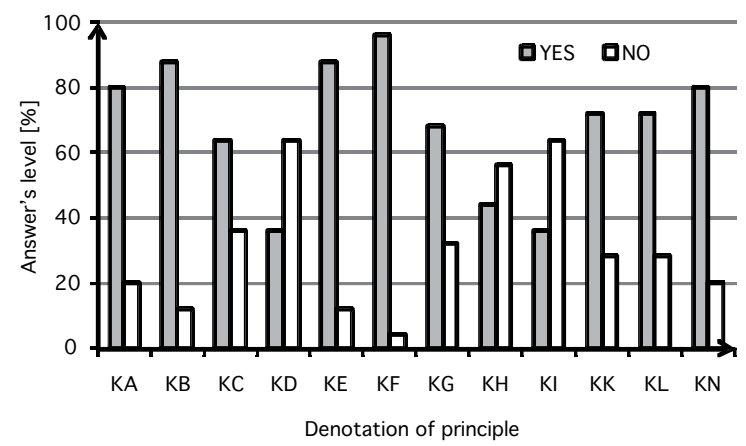

Fig. 3 Supervisor's assessment characteristics based on the 12 golden rules - rating structure

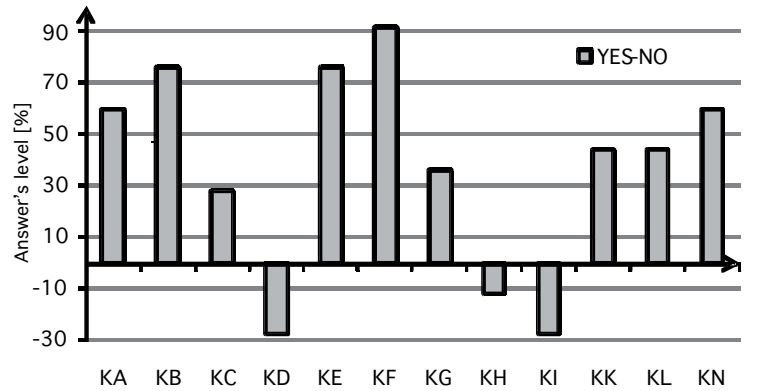

a) Denotation of principle

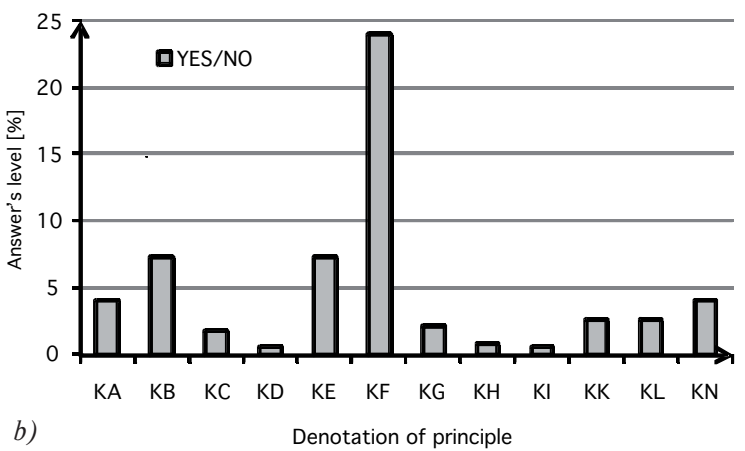

Fig. 4 Supervisor's assessment characteristics based on the 12 golden rules.

a) difference $Y E S-N O$, b) quotient $Y E S / N O$
An ability of KF - Directing and requiring of employees is a top-rated feature of superior among the respondents, which amounted to $96 \%$ of YES. Features: KB - To communicate about goals of actions and $\mathrm{KE}$ - To give support during performance of tasks were also very high assessed ( $88 \%$ of YES). Unfortunately according to the interviewed the supervisor KD - Does not Ask staffs about advice, KI - Does not thank openly ( $64 \%$ of NO).

The difference and quotient of the answers in case of the 12 golden rules are shown in Fig. 4.

Only in 3 cases: KD - Asks staffs about advice, KH - Prizes for good work and KI Thanks openly the difference YES-NO was below 0 . It means that only in these 3 cases the workers answered NO more often than YES. If it comes to the quotient of YES/NO, it is possible to be seen that in the case of element KF - Directs and requires, respondents answered YES 24 almost times more often than NO.

Results of characteristics of supervisors based on the Toyota's principles are presented in Table 4. Their graphic interpretation is presented in Fig. 5.

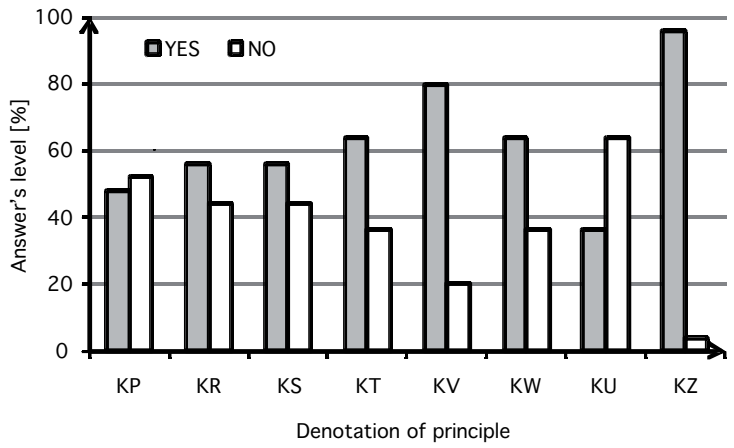

Fig. 5 Supervisor's assessment characteristics based on the Toyota's principles - rating structure

The feature: KZ - To be success-driven received the highest score - $96 \%$ of YES. KV - To be confident while decision-making also was assessed highly $-80 \%$ of respondents said YES.

Respondents stated at the same time that KU - the behavior of their supervisor does not inspire for learning ( $64 \%$ of NO).

The difference and quotient of the answers in case of the Toyota's principles are shown in Fig. 6.

Assessment structure according to the Toyota's principle

\begin{tabular}{|c|c|c|c|c|c|c|c|c|}
\hline \multirow{2}{*}{ Result } & \multicolumn{9}{|c|}{ Denotation of principle [\%] } \\
\cline { 2 - 11 } & KP & KR & KS & KT & KV & KW & KU & KZ \\
\hline YES & 48 & 56 & 56 & 64 & 80 & 64 & 36 & 96 \\
\hline NO & 52 & 44 & 44 & 36 & 20 & 36 & 64 & 4 \\
\hline
\end{tabular}



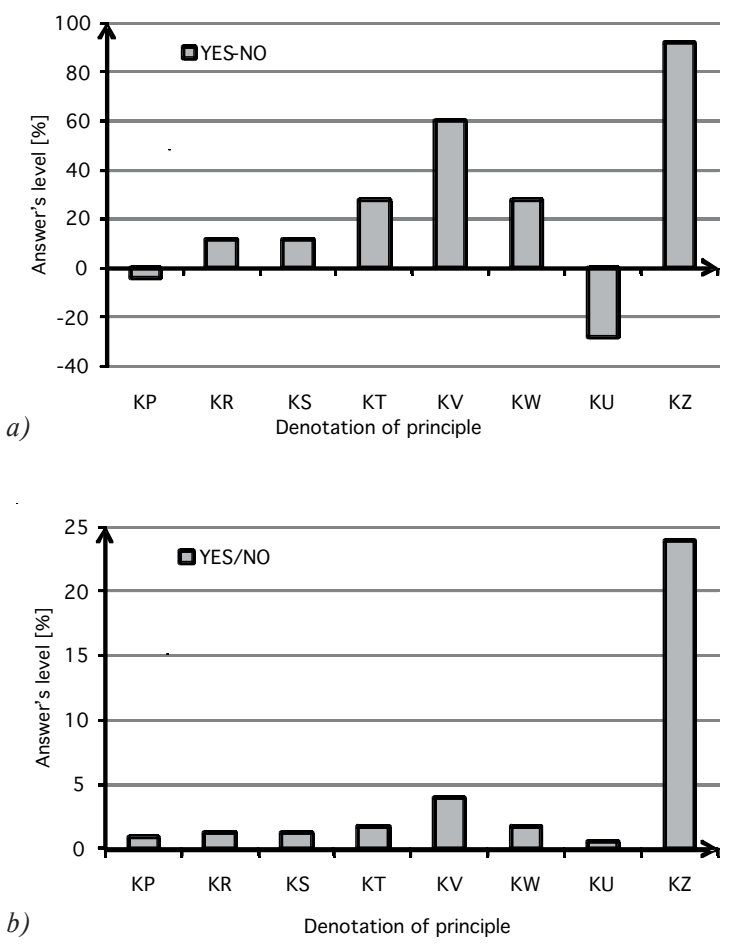

Fig. 6 Supervisor's assessment characteristics based on the Toyota's principles:

a) difference YES-NO, b) quotient YES/NO.

Only in 2 cases: $\mathrm{KP}$ - Improves work in his team and $\mathrm{KU}$ - His behavior inspires for learning the difference YES-NO was below 0 . It means that only in these 2 cases the workers answered NO more often than YES. If it comes to the quotient of YES/NO, in the case of element $\mathrm{KZ}$ - Is success-driven respondents answered YES 24 almost times more often than NO.

\section{Conclusion}

Suitability of the $4 \mathrm{E}+1 \mathrm{P}$, the 12 golden rules and the 8 Toyota's principles for assessment of leadership traits was determined for a supervisor from one of the Polish companies. Quantitative comparison of acceptance level for the traits contained in the principles was made. Impact of personal traits of the employees on the acceptance of manager traits was also determined.

Multi-aspect analysis of the results points to the suitability of the $4 \mathrm{E}+1 \mathrm{P}$ principles, the 12 golden rules, the Toyota's principles for determination of leadership traits in supervisors. The obtained results are characteristic of the manager, which emphasizes sensitivity of the adopted research methodology to a variety of factors.

The employees of the research company described in BOST surveys their supervisor, indicating his main features. They claimed that he:

- 4E - Knows how to implement decisions,

- KB - Communicates about goals of actions,

- KE - Gives support during performance of tasks,

- KF - Directs and requires,

- KV - Is confident while decision-making,

- KZ - Is success-driven,

but unfortunately the same time he:

- 1E - Is not full of enthusiasm all day long,

- KD - Does not ask staffs about advice,

- KI - Does not thank openly,

- KU - His behavior does not inspire for learning.

\section{References}

[1] Ed. and Scientific Elaboration BORKOWSKI, S., BLASKOVA, M., HITKA, M.: Toyotarity. Motivation Features of Managers, Pub. Makovetsky, Dnipropetrovsk, 2009.

[2] BORKOWSKI, S.: Management Principles from Toyota in Questions (in Polish), Wyniki badan BOST, Pub. PTM. Warszawa, 2009.

[3] BORKOWSKI, S.: Servqual Method, Teoria i praktyka, Pub. PTM. Warszawa, 2009.

[4] WELCH, J., WELCH, S.: Winning (in Polish), Pub. Emka, Warszawa 2005.

[5] NICKLES, W. G.: Understanding Business (in Polish), Bellona, Pub. Warszawa 1995.

[6] JEFFREY, K.: The Toyota Way: 14 Management Principles from the World's greatest Manufacturer (in Polish), Pub. MT Biznes, Warszawa 2005. 